\title{
Análise de conjuntura em saúde: aspectos conceituais, metodológicos e técnicos
}

\author{
Conjuncture Analysis of the Health: conceptual, methodological and \\ technical aspects
}

Camila Ramos Reis', Jairnilson Silva Paim ${ }^{1}$

DOI: $10.1590 / 0103-1104202113017$

RESUMO A produção científica em política de saúde cresceu nos últimos anos. No entanto, a revisão crítica dessa literatura aponta pouca articulação entre as dimensões teórica e empírica nas pesquisas realizadas, bem como certa rarefação teórica. Algo semelhante ocorre nos estudos de análise de conjuntura, que têm como foco o processo político, as relações de poder e a produção de fatos políticos em saúde. Daí a relevância de indagar quais os componentes teóricos, metodológicos e técnicos passíveis de serem utilizados nas pesquisas de análise de conjuntura em saúde e como articulá-los numa investigação concreta. O presente artigo tem como objetivo descrever conceitos e procedimentos metodológicos utilizados numa análise de conjuntura em saúde recente, a partir de uma pesquisa realizada. Com base no trabalho empreendido, discute a dificuldade em realizar pesquisas sobre análise de conjuntura em saúde, por conta da ausência de manual acerca de como fazer e da falta de detalhamento dos passos metodológicos utilizados em diversas publicações. Ainda assim, conclui que o relato apresentado pode contribuir para a sistematização dos passos necessários para a realização dessas análises e para justificar e orientar uma atividade prática com vista às mudanças da realidade.

PALAVRAS-CHAVE Políticas de saúde. Análise de situação. Metodologia.

ABSTRACT Scientific production in health policy has grown in recent years. However, the critical review of this literature points to little articulation between the theoretical and empirical dimensions in the research carried out, as well as a certain theoretical rarefaction. Something similar occurs in studies of conjuncture analysis that focus on the political process, power relations and the production of political facts in health. Hence the relevance of inquiring which theoretical, methodological and technical components are likely to be used in health analysis research and how to articulate them in a concrete investigation. This article aims to describe concepts and methodological procedures used in an analysis of the recent health situation, based on a research carried out. Based on the work I undertake, it discusses the difficulty in conducting research on the conjuncture analysis of the health, due to the absence of a manual on how to do it and the lack of detail on the methodological steps used in several publications. Even so, it concludes that the presented report can contribute to the systematization of the necessary steps to carry out these analyzes and to justify and guide a practical activity with a view to changing reality.

1 Universidade Federal da KEYWORDS Health policy. Analysis of situation. Methodology.

Bahia (UFBA), Instituto

de Saúde Coletiva (ISC) -

Salvador (BA), Brasil.

camila.ramos@ufba.br 


\section{Introdução}

Nos últimos anos, houve um crescimento da produção científica sobre políticas de saúde no Brasil com diferentes enfoques conceituais e teórico-metodológicos ${ }^{1-6}$. No entanto, observa-se pouca articulação entre os momentos teórico e empírico da pesquisa, assim como certa 'rarefação teórica'7. Evidências nessa perspectiva foram assinaladas em publicação recente ${ }^{\mathbf{8}}$.

Os estudos sobre a análise de conjuntura podem ser incluídos na 'Análise política em saúde'9 e têm como foco o processo político, as relações de poder e a produção de fatos políticos em saúde ${ }^{10}$. No caso do Brasil, os primeiros estudos em Política de Saúde tinham um caráter histórico, com recorte de períodos, referidos como 'conjunturas'11-13. Outros, porém, explicitavam o interesse nas análises de conjunturas, esboçando definições, noções, conceitos e enfoques teórico-metodológicos ${ }^{14-16}$.

De um modo geral, as dissertações e teses produzidas em Política, Planejamento e Gestão em Saúde (PP\&GS) apresentam um capítulo de metodologia, contemplando elementos teóricos e o detalhamento de procedimentos de coleta e análise de dados. Entretanto, quando transformados em artigos para publicação, esses produtos se apresentam mais resumidos para atender as normas dos periódicos, de modo que tendem a sacrificar o referencial teórico.

Contudo, a possibilidade aberta para a divulgação de estudos de revisão sistemática e de questões metodológicas, têm propiciado a publicação de parte desse referencial teórico-metodológico. Assim, Campos e Bataiero ${ }^{17}$ sistematizaram diferentes concepções acerca de necessidades de saúde, a partir de tendências das práticas de saúde, enquanto Lins e Cecílio ${ }^{18}$ apresentaram um esquema analítico para embasar estudos sobre organizações. Luzuriaga e Bahia' ${ }^{19}$ procederam a um mapeamento dos estudos comparados com o intuito de orientar a análise de políticas e sistemas de saúde na América Latina. No âmbito internacional, podem ser mencionadas contribuições para a análise comparada de sistemas de proteção social 20 e políticas e sistemas de saúde ${ }^{21}$.

No caso da análise de conjuntura em saúde, o primeiro estudo que explicitou o enfoque teórico-metodológico no Brasil foi publicado sob a forma de livro ${ }^{14}$. Este procurou apreender a forma de disposição do poder através da análise das instituições médicas, considerando duas conjunturas específicas (1960/1964 e 1968/1974), quando teria havido uma transformação dessas instituições ligada ao projeto de hegemonia do bloco do poder na formação social brasileira. O estudo apresenta o modelo econômico-político, analisa o panorama econômico internacional, aponta iniciativas referentes ao discurso do setor privado e relaciona o cenário da saúde à conjuntura social e política. Ele também considerava que, para investigar a conjuntura, seria necessário compreender a estrutura do poder de uma formação social, utilizando o enfoque histórico-estrutural, marxista em suas origens, mas buscando a orientação weberiana para contornar a acentuação excessiva dos aspectos estruturais na análise de conjunturas políticas.

Teixeira, Jacobina e Souza ${ }^{15}$, realizaram uma análise do processo político, considerando as questões nacionais e internacionais, com o foco na conjuntura pós-1974. Já Paim ${ }^{16}$, indicou que para pensar as políticas de saúde em uma dada conjuntura, seria necessário identificar as contradições resultantes do processo de acumulação capitalista e as suas mediações com as condições de saúde das diferentes classes sociais, bem como os enfrentamentos no âmbito da sociedade. Analisou aspectos econômicos, políticos e ideológicos, a partir de elementos teóricos 'gramscianos', ilustrando certas relações entre saúde e a estrutura social.

Em uma revisão sistemática recente foram identificados diversos estudos sobre análise de conjuntura ${ }^{22}$. Alguns deles consideraram fatos, forças existentes e atores, embora faltem embasar a análise política em saúde e explicitar categorias analíticas como poder político, atores/sujeitos e ação. 
Daí a relevância de indagar: Quais os componentes teóricos, metodológicos e técnicos passíveis de serem utilizados nos estudos de análise de conjuntura em saúde e como articulá-los numa pesquisa? Nessa perspectiva, o presente artigo tem como objetivo descrever conceitos e procedimentos metodológicos utilizados numa análise de conjuntura em saúde recente, a partir de uma investigação concreta.

\section{Aspectos teórico-metodológicos}

O presente artigo, ao tomar como foco a análise de conjuntura, elabora um referencial teórico recorrendo à contribuição de diversos autores, desde clássicos ${ }^{23-28}$ aos contemporâneos ${ }^{29-31}$. A opção por esses estudos, deu-se pela possibilidade de identificar categorias de análise que ajudem a interpretar a sociedade, bem como contextualiza-las para análise da realidade brasileira, a exemplo das diversas concepções de Estado, do 'bloco histórico', da 'hegemonia', 'revolução passiva' e 'transformismo'. Nesse sentido, podem ser referidas algumas obras de Marx e Engels onde apresentam a teoria sobre o Estado e sua relação com as 'classes dominantes' da sociedade, a 'luta de classes', 'classe' e 'frações de classe '23,32-35. Com a revolução socialista, as discussões sobre a elaboração teórica do 'imperialismo' e os estudos sobre o chamado 'partido leninista' seguiram na mesma perspectiva ${ }^{24,36}$. No ocidente, outras reflexões foram produzidas sobre 'estruturas', 'movimentos orgânicos e conjunturais'26-28.

No Brasil, podem ser destacados os estudos já referidos ${ }^{29-31}$, assim como a investigação sobre a Reforma Sanitária Brasileira (RSB) ${ }^{37}$. Neste estudo, Paim ${ }^{\mathbf{3 7}}$ discute brevemente certa problemática do marxismo como as relações entre infraestrutura e superestrutura, bem como a concepção ampliada do Estado, consideradas complexas e não resolvidas, de modo que o aprofundamento dessa discussão ultrapassa o propósito do presente artigo.
Para o desenvolvimento do momento empírico, o artigo sugere o desenho de estudo de caso $^{\mathbf{3 8}}$ e sistematiza certos procedimentos sobre como realizar uma análise de conjuntura 22,39-41.

Nos próximos tópicos, são apresentados os principais conceitos do referencial teórico elaborado, as suas respectivas definições e sistematizações, assim como os procedimentos para o tratamento do material empírico da pesquisa.

\section{Referencial teórico}

A estrutura social se refere às determinações econômicas, políticas e ideológicas de cada formação social, caracterizadas pelo modo de produção. A sociedade é representada pela estrutura econômica, definida como infraestrutura, ou seja, a base material formada por forças produtivas e por relações de produção e sobre a qual se ergue uma superestrutura ideológica e jurídica. Esses dois níveis (infraestrutura e superestrutura) se articulam e se influenciam mutuamente, formando uma estrutura social organizada e complexa ${ }^{\mathbf{4 2}}$.

A superestrutura ideológica expressa as representações sociais, caracterizando-se como um instrumento de dominação de uma classe social sobre a outra. Assim, essa instância jurídico-política abrange os aparelhos institucionais que visam regulamentar o funcionamento da sociedade através do Estado ${ }^{\mathbf{4 2}}$.

\section{Conjuntura}

A conjuntura se refere às inter-relações das diversas forças (sociais, políticas, econômicas) numa situação histórica determinada. Expressa a correlação de forças numa determinada estrutura, segundo interesses próprios. Ou seja, os elementos mais dinâmicos, em que se destaca a luta de classes ${ }^{\mathbf{4 2}}$.

Noutra perspectiva, a 'conjuntura' está relacionada às características que influenciam o mercado em um período mais curto e 
determina o ciclo econômico ${ }^{26}$. Diz respeito às características provisórias da 'situação econômica', aquelas que 'determinam o mercado' (ciclo econômico) e a 'oscilação da situação econômica'31. Está relacionada às questões econômicas, sendo fundamental a sua análise para antecipar, dentro de certo limite, o ciclo econômico.

Já outros autores 39,40 destacam que, para analisar a conjuntura, haveria que observar, integralmente, a estrutura da sociedade e não apenas a dimensão econômica. Implica uma pesquisa interessada no sentido de produzir uma intervenção, apontar os problemas, direcionar as ações de uma organização ou mesmo definir estratégias e táticas das forças sociais.

A conjuntura está ligada à 'política imediata' ('as táticas', aquelas questões de curto prazo, transitórias). Já a situação remete à 'estratégia', ou seja, àquelas questões de longo prazo, que podem propiciar transformações na estrutura da sociedade ${ }^{26}$.

$\mathrm{Na}$ pesquisa realizada ${ }^{\mathbf{3}}$, considerou-se relevante conceber a conjuntura como a estrutura social em movimento ${ }^{37}$, possibilitando investigar tanto a base econômica, como a superestrutura político-ideológica em um determinado período.

\section{Estratégias e táticas}

Em relação à estratégia, é necessário identificar a articulação e a definição de um conjunto de meios e forças, tendo em vista realizar objetivos gerais ou 'projetos' mais globais, com objetivos e linhas de ação $0^{39}$. A estratégia é caracterizada pela forma como as organizações se comportam em relação à superação dos problemas ${ }^{30}$.

Duas estratégias emergiram da história como possibilidades de conquista do poder: a 'guerra de movimento' ou 'tomada do poder' e a 'guerra de trincheiras' ou 'guerra de posição'25. A 'guerra de movimento' é caracterizada pela conquista frontal do poder, através da luta física, embora a 'guerra de posição' não exclua a 'guerra de movimento', isto é, a possibilidade de luta pela tomada do poder (assalto ao poder). Na 'guerra de trincheira' ou 'guerra de posição', a estratégia é pensada a longo prazo, requer organização das massas e está ligada ao conceito de hegemonia ${ }^{31}$, pois visa à disputa do poder a partir da conquista de posições importantes, políticas e culturais, para sua construção.

Nesse sentido, cabe pensar a hegemonia de forma articulada ao Estado e essa relação pode ser compreendida a partir da oposição entre as estratégias da 'guerra de movimento' e da 'guerra de posição', considerando a classe social, pois ela é fundamental para entender a hegemonia ${ }^{26}$.

Desta forma, a estratégia é usada como uma maneira de ganhar espaço e estabelecer as condições favoráveis. Está relacionada às formas de se organizar para conseguir o poder. Nesse sentido, se vincula à política, sendo a política referida à distribuição do poder e aos objetivos definidos; já a estratégia é ligada às formas de implementar essa política, sendo o instrumento utilizado para alcançá-la. Assim, pode-se ter uma política que apresenta como objetivo transformação ou conservação ${ }^{30}$. Torna-se necessário identificar as estratégias existentes, qual o objetivo da política implantada, se há transparência ou opacidade nas ações e quais as formas de atuação dos atores e sujeitos envolvidos para alcançar o poder.

Ademais, a 'guerra de posição' ou 'guerra de trincheiras' inclui as táticas e ações empreendidas na conjuntura. Desta forma, os atores sociais adotam a tática de resistência, acumulação de forças e conquistas parciais no jogo do poder ${ }^{27}$. Assim, a partir da identificação das táticas usadas pelas forças políticas em disputa, torna-se possível perscrutar uma conjuntura.

\section{Bloco histórico}

O conceito de 'bloco histórico’ oferece pistas para que a análise de conjuntura ultrapasse o econômico. Embora a base da relação de força seja determinada pela relação econômica, os níveis 'político e ideológico' são dominantes nesse processo ${ }^{27}$. 
Assim, o ‘bloco histórico’ é formado pela estrutura (economia) e a superestrutura (ideologia e política), sendo uma expressão das relações sociais de produção ${ }^{26}$. É caracterizado pela relação entre grupos dominantes e dominados, a partir de contradições e conflitos existentes, na qual a ideologia aparece como suporte para esse bloco que tem na superestrutura a sociedade civil e a sociedade política ${ }^{44}$. A sociedade civil é formada pelo conjunto de organizações responsáveis por difundir a ideologia e construir a hegemonia. Já a sociedade política, equivalente ao Estado restrito, é aquela formada pelos mecanismos que garantem a manutenção da força pela classe dominante ${ }^{29}$.

\section{Relação de força}

Em um estudo sobre estrutura de uma sociedade, é necessário considerar que existem movimentos que permanecem ('movimentos orgânicos') e outros que são temporários ('ligados à conjuntura'). Desta forma, é importante identificar esses movimentos, pois a partir disso podem-se caracterizar as forças existentes, sejam elas de conservação ou de mudança. Essa distinção se aplica a qualquer situação, seja ela de crise ou de progresso ${ }^{27}$.

Usa-se a noção de 'relação de força' para entender adequadamente a luta hegemônica, a constituição da sociedade civil e seus elos com o Estado e na formação de uma consciência crítica da realidade. Dessa forma, as relações de força estão presentes, sejam explicita ou implicitamente, nas diversas 'análises de situações'. Nesse enfoque, a essência da práxis política é reconhecida a partir da leitura de Maquiavel, de modo que, para a análise de uma situação, é necessário examiná-la da forma como ela é e não como deveria ser 27(19-46).

Para se proceder a uma análise de situação e das relações de forças, é importante considerar o momento subjetivo (deve ser), assim como o momento objetivo (o ser). As diferenças entre fenômenos da conjuntura e fenômenos orgânicos podem ser aprendidas com a distinção entre a pequena e a grande política ${ }^{27}$.
O estudo sobre como se devem estabelecer os níveis das relações de força pode ser interessante para despertar o interesse pela realidade, inspirado na proporção da análise concreta de situações concretas ${ }^{\mathbf{2 4}}$, essência do marxismo.

É comum nas análises das relações de força o pesquisador apresentar o fato e interpretá-lo como uma causa para certo problema. Entretanto este procedimento pode resultar em erro, pois é necessário levar em consideração alguns critérios no momento de analisar as relações de forças. É preciso considerar que existem relações de forças sociais estreitamente ligadas à estrutura (essas forças não podem ser facilmente modificadas) e há relações de forças políticas alcançadas pelos vários grupos sociais que podem ser analisados a partir dos diversos momentos (político coletivo, econômico-corporativo, solidariedade e ético-político).

Essas relações podem estar associadas à análise da hegemonia, e nesse sentido, é importante examinar a correlação de forças. Finalmente, cabe considerar a relação de força militar, que abrange a característica técnico-militar (opressão) ou político-militar (desagregação social do povo oprimido) ${ }^{27}$.

A análise 'gramsciana' de conjuntura supõe, portanto, o exame de um feixe de relações (relações de força), que implica o conhecimento do seu desenvolvimento desigual em cada um dos níveis que articuladamente compõem a totalidade social ${ }^{29}$. Nesse sentido, cabe investigar relações contraditórias que atravessam a infraestrutura e a superestrutura, identificando os fatos políticos produzidos, a atuação dos sujeitos e a correlação de forças políticas e sociais em certos recortes do tempo.

\section{Alguns passos para a análise de conjuntura}

No que diz respeito aos passos para realizar a análise de conjuntura, é necessário ter claro o objeto e os objetivos que se pretende alcançar. O objeto seria a definição do local e o 
tempo que se quer analisar ${ }^{40}$. Assim, o objeto pode corresponder à conjuntura referente ao período de governo, como por exemplo Dilma Rousseff (2011-2016). Já os objetivos contemplam as análises da situação (social, econômica, política e ideológica) e das políticas de saúde do período. Desse modo, é possível explicar possíveis alterações no processo da RSB e no desenvolvimento do SUS, levando em consideração a ação, a atuação e a capacidade de reação dos sujeitos e atores envolvidos. A partir dos fatos, dos cenários e da correlação de forças na análise da conjuntura, procura-se identificar as estratégias e táticas acionadas.

\section{Poder}

Para fins de pesquisa, fez-se necessário distinguir o conceito de poder setorial ${ }^{30,45} \mathrm{e} o$ poder societário ${ }^{46}$.

O poder, para Testa ${ }^{30,45}$, é considerado a partir de dois eixos, o cotidiano (atuação diária, expressa no que e como fazer das organizações) e o societário (construção da sociedade, seja a partir do pensar uma nova proposta ou mesmo de reproduzir o que já existe). A partir dessas dimensões do poder ocorreriam os processos de disputas no espaço onde se insere o processo político, podendo envolver transformações e decisões. Assim, o poder é desenvolvido através do papel do Estado, expresso a partir do seu exercício, isto é, do processo político e das ações implementadas por meio das políticas implantadas.

Esse poder diz respeito à capacidade de mobilizar informações, recursos e grupos sociais, tendo três tipos: técnico, administrativo ou político. O técnico é expresso pelos conhecimentos e informações; o administrativo por meio dos recursos financeiros e materiais; e o político através da mobilização de grupos sociais.

No que diz respeito ao poder societário, considera-se a existência do poder econômico (riqueza), do poder político (força) e do poder ideológico (saber) ${ }^{\mathbf{4 6}}$. O poder econômico está relacionado ao poder do capital e direciona o desenvolvimento das políticas. O poder político se caracteriza pelo uso da força exercida pelo Estado. Já o poder ideológico diz respeito aos saberes presentes na sociedade e seu processo de socialização, especialmente por meio da mídia, da religião, da arte e da educação.

Cabe ainda mencionar, que o poder em saúde $\mathbf{4 5}$ pode ser entendido como um recurso (poder econômico, político e ideológico), como capacidade de ação e como relação.

\section{Fatos históricos, sociais e políticos}

Numa investigação, pode ser considerado um 'fato' aquilo que trouxe alguma repercussão na sociedade, cabendo mencionar a existência de três tipos de 'fatos': o histórico, o social e o político.

$\mathrm{O}$ 'fato histórico' $\mathbf{4 7 , 4 8} \mathrm{diz}$ respeito àquelas manifestações dos indivíduos ou da sociedade que produzem algum significado para o desenvolvimento social, sendo necessário ter um sistema de referência para distinguir o valor. Além disso, mantém-se importante no decorrer da história independente do pesquisador/historiador.

Durkheim ${ }^{\mathbf{4 9}}$ define 'fato social' como algo (uma 'coisa') que determina o agir do indivíduo - uma coerção do exterior (externalidade) ou uma generalidade da sociedade - que possui uma existência própria. Seria a maneira coletiva de agir, pensar e sentir, ou o poder de coerção externa que exerce ou é capaz de exercer sobre os indivíduos que os distingue dos demais fenômenos da sociedade.

O 'fato político' corresponde a um fato social produzido nas relações entre o Estado e a sociedade, por meio de interações de conflitos ou interesses ${ }^{50}$. Assim, privilegia-se a identificação dos fatos políticos que ocorrem na sociedade no período estudado, para que seja possível interpretá-los e identificar os interesses, conflitos e projetos relacionados.

\section{Cenários}

Os cenários são os espaços nos quais as ações da esfera social e política se desenvolvem. É uma 
projeção hipotética das configurações possíveis de elementos variáveis (variantes), que podem situar-se no plano político mais geral, bem como nos planos político-institucional, econômico, demográfico e epidemiológico ${ }^{51}$.

O cenário é onde se desenvolve a ação e é caracterizado por Testa ${ }^{30}$ como um espaço social que envolve atores sociais, enquanto um campo de forças onde o poder é uma categoria central. Esse espaço social seria a combinação de diversos campos de forças, com objetivos diferentes, dentro do setor saúde. Seria nesse espaço onde acontecem os processos de discussão, conflitos, decisões, entre outros. Está sujeito a transformações e mudanças constantes, seja em termos conjunturais ou em relação ao poder institucional, sendo o local de disputa de poder cotidiano e societário. Desta forma, faz-se necessário identificar os cenários existentes no período em estudo, pois indicam os campos de forças que podem ser modificados a depender da questão em disputa.

Numa conjuntura onde muitos fatos acontecem, ocorrendo diversas disputas com objetivos diferentes, aparecem distintos cenários (as ruas, o parlamento, os conselhos de saúde, a burocracia das instituições, as redes sociais etc.), sendo desenvolvidas variadas ações e processos, sejam eles de conflitos, discussões, cooperações, negociações e decisões.

\section{Sujeitos e atores sociais e políticos}

Um sujeito social é aquele que supera a condição de indivíduo e é embasado por uma ideologia. Já um ator social seria aquele sujeito que tem capacidade de inserir uma pauta no debate político em torno da elaboração de propostas de intervenção. Testa ${ }^{30,45}$ aponta que um ator político é capaz de introduzir temas na agenda do Estado. E os sujeitos (individuais e coletivos), para serem constituídos, passam por um processo de aprendizagem que implica "auto formação e a transformação"52(37).

Os sujeitos se constituem por meio da ideologia, trabalho e das lutas presentes na sociedade $^{53}$. Pode-se observar o desenvolvimento de uma atitude e/ou uma aptidão crítica em distintos níveis: individual, comunitário, institucional, político e estatal ${ }^{54}$. A depender da consciência crítica, esse ator pode se transformar em um sujeito transformador. Assim, esses sujeitos e atores podem revelar como se deu a correlação de forças, apontando se as forças são de confronto, coexistência ou mesmo de cooperação.

Testa $^{30}$ diferencia um grupo social de uma classe social. Afirma que um grupo social seria aquele possível de se identificar que realiza o trabalho concreto, e traz o exemplo dos profissionais de saúde. A classe social é uma categoria analítica, sendo difícil de ser identificada facilmente na sociedade. É necessário entender analiticamente a classe para que assim se possa compreender a realidade. Ambos, grupo e classe, possuem interesses.

As classes resultam de lutas sociais, de sua ideologia, organização, interesses de classe e liderança política, cultural e moral ${ }^{55}$. Essas classes podem estar organizadas em um momento ou em uma situação de dominação. Assim, para fins de análise da estrutura social num dado período estudado, faz-se necessário entender a estrutura de classe no Brasil e como ela foi se organizando e se localizando na sociedade.

Um sujeito coletivo pode ser um grupo social ou mesmo uma classe social, mas para que uma classe exerça influência política ela precisa ser conformada em um grupo. Sendo assim, a constituição de uma classe pode ser feita com base em um mesmo objetivo para todos os componentes da classe ou mesmo com base em diversos objetivos para agrupamentos de sujeitos sociais individuais, que juntos conferem situações parecidas para o grupo ${ }^{30}$.

\section{Desenhos de estudo e procedimentos técnicos de coleta e análise de dados}

A investigação de uma conjuntura pode acionar um estudo de caso de caráter histórico, por 
meio de pesquisa documental, sobre fatos produzidos num período e divulgados na mídia, em publicações oficiais e sites. A utilização do estudo de caso se dá pelo fato da pesquisa buscar compreender acontecimentos sociais complexos e contemporâneos relacionados à saúde, além de utilizar várias fontes de dados ${ }^{\mathbf{3 8}}$.

Nos tópicos a seguir, são sistematizadas algumas fontes de dados, procedimentos de coleta e registro, bem como de análise e interpretação.

\section{Fontes de dados}

Na análise de conjuntura em saúde no Brasil podem ser acionadas, por exemplo, as seguintes fontes: a) Entidades de saúde; b) Mídia: notícias e publicações de jornais, revistas, sites, blogs, entre outros; c) Publicações Oficiais; d) Agências e órgãos governamentais: e) Programas de governo; f) Documentos de posição, matriz de acompanhamento e linhas do tempo dos eixos de pesquisa do Observatório de Análise Política em Saúde (OAPS) - http:// www.analisepoliticaemsaude.org - e outras publicações científicas que forneçam dados e informações úteis para a análise de conjuntura; g) Datafolha; h) Sistemas de informação: Datasus, Instituto Brasileiro de Geografia e Estatística (IBGE), Associação Nacional de Saúde Suplementar (ANS), Instituto de Pesquisa Econômica Aplicada (Ipea), Banco Central, Tribunal Superior Eleitoral (TSE).

\section{Coleta de dados}

O registro de dados decorrente do levantamento de documentos oficiais e matérias da mídia escrita podem ser armazenados em arquivos impressos e/ou digitalizados e analisados utilizando matrizes bidimensionais categóricas (manuais ou processadas em computador) e organizadas da seguinte forma: a) notícias obtidas nos sites das entidades, agências e órgãos governamentais da saúde; b) do site Saúde Legis; c) notícias da mídia impressa e eletrônica; d) levantamento e sistematização dos fatos.
No caso dos dados secundários coletados nos sistemas de informação, esses podem ser organizados a partir da definição dos indicadores que se pretende analisar.

\section{Análise de dados}

A partir do material empírico coletado e analisado, com a identificação dos principais fatos políticos relacionados à saúde, pode ser descrita a situação nas dimensões social, econômica, política, ideológica e sanitária.

De acordo com os instrumentos citados, os fatos/notícias podem ser classificados para a análise considerando algumas categorias sistematizadas no referencial teórico:

1. Fatos históricos, sociais e políticos;

2. Bloco histórico:

a. Estrutura econômica;

b. Superestrutura político-ideológica (sociedade civil e sociedade política);

3. Relação de forças:

a. Classe Dominante;

b. Classe Subalterna;

4. Poder:

a. Econômico;

b. Político;

c. Ideológico;

5. Cenários:

a. Estratégia;

b. Táticas. 
Desse modo, torna-se possível considerar a totalidade do processo, estabelecendo inter-relações entre os dados levantados, em cada momento de análise, relativos aos projetos, sujeitos, estratégia e táticas na conjuntura ${ }^{39,40}$.

\section{Comentários finais}

A proposta teórico-metodológica apresentada neste artigo foi elaborada para uma pesquisa sobre uma conjuntura recente no Brasil num Curso de Pós-Graduação em Saúde Coletiva ${ }^{\mathbf{4 3}}$.

A sua utilização pode contribuir para a análise de sujeitos e projetos em disputa na sociedade, bem como sobre a 'correlação de forças', as coalizões que se movimentam, as 'estratégias', forças políticas, bases sociais, a 'estrutura de classe' e o 'bloco histórico', enquanto 'totalidade social'25.

Neste sentido, para realizar uma análise de conjuntura em saúde, caberia definir o tempo (período de estudo) e o espaço (local) referentes ao objeto que se pretende estudar.

Embora não seja pretensão do estudo fornecer uma 'receita' metodológica, como se fora um manual, trata-se de uma alternativa que pode ajudar a ir além dos artigos de opinião, comentários e análises políticas ou mesmo reflexões de 'cientistas políticos' ou 'economistas', que nem sempre apresentam fundamentação teórica e base empírica consistentes.

A contribuição do estudo é focar na análise de conjuntura da saúde, embora dialogando com informações do contexto econômico, ideológico e político mais amplo. Ainda assim, não visa extrapolar os passos sistematizados para a análise de qualquer política pública.

No caso específico da política pública de saúde, enquanto resposta social aos problemas e necessidades de saúde e seus determinantes, a proposta pode contemplar a organização e gestão do sistema e dos serviços, o modelo de atenção, o financiamento, além das questões sanitárias, epidemiológicas e os fatos produzidos pelos sujeitos numa dada correlação de forças.

Cabe reconhecer, no entanto, a dificuldade em realizar pesquisas sobre análise de conjuntura em saúde, não só pela dificuldade de localizar algum manual acerca de como fazer, mas também devido às publicações disponíveis pouco detalharem os passos metodológicos utilizados pelas investigações realizadas.

Assim, faz-se necessário um aprofundamento dos aspectos teóricos e metodológicos ${ }^{56} \mathrm{e}$ que, ao lado do 'adensamento teórico'7, seja realizado um esforço adicional voltado para a explicitação dos procedimentos técnicos de coleta, processamento, análise e interpretação dos dados.

Desta forma, é possível caracterizar as questões centrais que se colocam em destaque na luta social e política, em um certo período de tempo ${ }^{39}$. Desse modo, a análise da distribuição do poder e suas expressões na sociedade ajudam a interpretar o bloco histórico, a hegemonia e os sujeitos presentes e atuantes em uma dada conjuntura. E essa análise de conjuntura, contemplando as 'relações de força', adquire significado se serve para justificar e orientar uma atividade prática, porquanto tais relações podem ser passíveis de mudanças ${ }^{\mathbf{2 7}}$.

\section{Colaboradores}

Reis CR (0000-0001-5646-4355)* e Paim JS (0000-0003-0783-262X)* contribuíram igualmente para a elaboração do manuscrito.
${ }^{*}$ Orcid (Open Researcher and Contributor ID). 


\section{Referências}

1. Pinell P. Análise sociológica das políticas de saúde. Rio de Janeiro: Fiocruz; 2010.

2. Pinto CM, Vieira-da-Silva LM, Baptista TVF. Ciclo de uma política de Saúde: problematização, construção da agenda. Institucionalização, formulação, implementação e avaliação. In: Paim JSP, Almeida-Filho N. Saúde Coletiva: teoria e Prática. Rio de Janeiro: MedBook; 2014. p. 69-82.

3. Federico L. Análise política em saúde: a contribuição do pensamento estratégico. Salvador: Edufba; 2015.

4. Vieira-da-Silva LM, Chaves SCL, Esperidião MA, et al. Análise sócio-histórica das políticas de saúde: algumas questões metodológicas da abordagem bourdieusiana. In: Teixeira CF, organizadora. Observatório de Análise Política em Saúde: abordagens, objetos e investigações. Salvador: Edufba; 2016. p. 15-40.

5. Machado CV, Lima LD, Baptista TWF. Políticas de saúde no Brasil em tempos contraditórios: caminhos e tropeços na construção de um sistema universal. Cad. Saúde Pública. Rio de Janeiro. 2017; 33(2):143-161.

6. Cerqueira SCC. O CONASS e as linhas de construção do SUS: análise política nos períodos 2006-2016. [tese]. Salvador: Universidade Federal da Bahia; 2019. $208 p$.

7. Schraiber LB. Engajamento ético-político e construção teórica na produção científica do conhecimento em Saúde Coletiva. In: Baptista TWF, Azevedo CS, Machado CV. Políticas, planejamento e gestão em saúde: abordagens e métodos de pesquisa. Rio de Janeiro: Fiocruz; 2015; p.33-58.

8. Vieira-da-Silva LM, Esperidião MA, Silveira AS, et al. A construção do campo da Saúde Coletiva e as políticas de saúde - Contribuições da Revista Ciência \& Saúde Coletiva. Ciênc. Saúde Colet. 2020; 25(12):4669-4680.

9. Paim JS. Análise política em saúde: um pensamento estratégico para a ação estratégica. In: Federico L.
Análise Política em saúde: a contribuição do pensamento estratégico. Salvador: EDUFBA; 2015. p. 279286.

10. Esperidião MA. Análise política em saúde: síntese das abordagens teórico-metodológicas. Saúde debate. Rio de Janeiro. 2018; 42(2):341-360.

11. Donnangelo MCF. Medicina e sociedade: o médico e seu mercado de trabalho. São Paulo: Pioneira; 1975

12. Braga JCS, Paula SG. Saúde e Previdência: estudo de política social. Rio de Janeiro: CEBES; 1981.

13. Oliveira JAA, Teixeira SMF. (Im) previdência social: 60 anos de história da Previdência Social no Brasil. Petrópolis: Editora Vozes-Abrasco; 1985.

14. Luz MT. As instituições médicas no Brasil. Instituição e estratégia de hegemonia. Rio de Janeiro: Graal;1979.

15. Teixeira CF, Jacobina RR, Souza AL. Para uma análise da conjuntura política em saúde. Saúde debate. 1980; (9):4-10.

16. Paim JS. As políticas de saúde e a conjuntura atual. Saúde debate. 1984; 15(16):8-15.

17. Campos CMS, Bataiero MO. Necessidades de saúde: uma análise da produção científica brasileira de 1990-2004. Interface, Comunic Saúde Educ. 2007; 11(23):605-618.

18. Lins AM, Cecílio LCO. Campos de intervenções organizacionais: a contribuição das ciências humanas para uma leitura crítica das propostas de gestão das organizações de saúde. Interface, Comunic Saúde Educ. 2007; 11(23):503-514.

19. Luzuriaga MJ, Bahia L. Aportes de los estudios comparativos para la comprensión de las políticas y sistemas de salud en países de América Latina. Cad. Saúde Colet. 2016; 24(1):55-62. 
20. Esping-Andersen G. As três economias políticas do Welfare State. Lua Nova. 1991; (24):85-116.

21. Marmor T, Wendt C. Conceptual frameworks for comparing healthcare politics and policy. Elsevier. 2012; 107(1):11-20.

22. Virgens JHA, Teixeira CF. Revisão da produção científica sobre análise de conjuntura: contribuição à análise política em saúde. Saúde debate. 2018; 42(2):377393.

23. Marx K. O dezoito Brumário de Louis Bonaparte. 2. ed. São Paulo: Centauro; 2000.

24. Lênin VI. Que fazer? São Paulo: Hucitec; 1978.

25. Gramsci A. Maquiavel, a política e o Estado Moderno. Rio de Janeiro: Civilização Brasileira; 1976.

26. Gramsci A. Cadernos do Cárcere. Volume 1: Introdução ao estudo da filosofia. A filosofia de Benedetto Croce. Rio de Janeiro: Civilização Brasileira; 1999.

27. Gramsci A. Cadernos do Cárcere. Volume 3: Maquiavel - Notas sobre o Estado e a política. Rio de Janeiro: Civilização Brasileira; 2000.

28. Gramsci A. Cadernos do Cárcere. Volume 5: O Risorgimento. Rio de Janeiro: Civilização Brasileira; 2002.

29. Portantiero JC. Gramsci Y el análisis de conyuntura (algumas notas). In: Portantiero JC. Los usos de Gramsci. México: Folio; 1983. p. 67-146.

30. Testa M. Pensamento estratégico e lógica de programação. O caso da saúde. São Paulo: Hucitec; 1995.

31. Liguori G, Voza P. Dicionário Gramsciano (1926-1937). São Paulo: Boitempo; 2017.

32. Marx K. Contribuição à crítica da economia política; tradução e introdução de Florestan Fernandes. 2. ed. São Paulo: Expressão Popular; 2008.

33. Marx K, Engels F. A ideologia alemã. São Paulo: Expressão Popular; 2009.
34. Marx K. As lutas de classes na França de 1848 a 1850. São Paulo: Boitempo; 2012.

35. Marx K, Engels F. Manifesto do partido comunista. Porto Alegre: L\&PM; 2015.

36. Lênin VI. Imperialismo, fase superior do capitalismo. São Paulo: Expressão Popular; 2012.

37. Paim JS. Reforma Sanitária Brasileira: contribuição para a compreensão e crítica. Salvador: EDUFBA; 2008.

38. Yin RK. Estudo de caso: planejamento e métodos. 3. ed. Porto Alegre: Bookman; 2005.

39. Souza HJ. Como se faz análise de conjuntura. Petrópolis: Vozes; 2014.

40. Silva LEP. Metodologia de análise de conjuntura. Estudos Teológicos. 1988; 28(3):305-315.

41. Alves JE. D. Análise de conjuntura: teoria e método. 2. ed. Rio de Janeiro: Inclusão Social em Debate; 2008.

42. Harnecker M. Os conceitos elementais do materialismo histórico. Rio de Janeiro: Graal; 1973.

43. Reis CR. A Reforma Sanitária Brasileira durante os governos Dilma: uma análise da conjuntura. [dissertação]. Salvador: Universidade Federal da Bahia; 2020. 215 p.

44. Portelli H. Gramsci e o bloco histórico. Rio de Janeiro: Paz e Terra; 1977.

45. Testa M. Pensar em saúde. Porto Alegre: Artes médicas; 1992.

46. Bobbio N. Estado, governo e sociedade. Rio de Janeiro: Paz e Terra; 1987.

47. Carr EH. O que é história? 3. ed. Rio de Janeiro: Paz e Terra; 1982.

48. Scharff A. História e verdade. 6. ed. São Paulo: Editora Martins Fontes; 1995. 
49. Durkheim E. As regras do método sociológico. 3. ed. São Paulo: Martins Fontes; 2007.

50. Alencar TOS. Notas sobre definições de fato social, histórico e político: subsídios para análise política em saúde. Observatório de Análise Política em Saúde. 2016 set 17. [acesso em 2020 out 25]. Disponível em: http://www.analisepoliticaemsaude.org/oaps/documentos/pensamentos/147428574757dfdob3e7102/.

51. Organización Panamericana de Salud. La Administración estrategica en SILOS. Washington DC: OMS 1992.

52. Dallmayr F. Para além da democracia fugidia: algumas reflexões modernas e pós-modernas. In: Souza J, organizador. Democracia hoje: Novos desafios para a teoria democrática contemporânea. Brasília, DF: UnB; 2001. p. 11-38.
53. Paim JS. Ensaio: Sujeitos da antítese e os desafios da práxis da Reforma Sanitária Brasileira. Saúde debate. $2017 ; 41(3): 255-264$.

54. Testa M. Decidir en salud: ¿̨Quén? ¿̨Cómo? Y ¿̨Porqué?. Salud Colectiva. 2007; 3(3):247-257.

55. Guimarães ASA. Estrutura e formação das classes sociais na Bahia. Revista Novos Estud. 1987; 18(2):5769.

56. Cruz SCV. Teoria e método na análise de conjuntura. Educ Soc. 2000. 21(72):145-152.

Recebido em 03/12/2020

Aprovado em 11/06/2021

Conflito de interesses: inexistente

Suporte financeiro: não houve 